\title{
Controle em Pós-Emergência e Características Germinativas DE AGRIÃOZINHO ${ }^{1}$
}

\author{
Postemergence Control and Germination Characteristics of Synedrellopsis grisebachii
}

\author{
GIANCOTTI, P.R.F. ${ }^{2}$, ALVES, P.L.C.A. ${ }^{3}$, YAMAUTI, M.S. ${ }^{4}$ e BARROSO, A.A.M. ${ }^{5}$
}

\begin{abstract}
RESUMO - O agriãozinho é uma planta daninha de grande importância em pastagens do Brasil e apresenta destacada agressividade, sendo seu controle, portanto, desejável para o sucesso da produção forrageira. O objetivo deste trabalho foi avaliar o controle químico de Synedrellopsis grisebachii na fase reprodutiva e as suas consequências sobre as características germinativas dos aquênios da planta daninha. Os tratamentos constaram da aplicação dos herbicidas glyphosate $\left(100,200,900\right.$ e $\left.1.800 \mathrm{~g} \mathrm{ha}^{-1}\right)$, paraquat $\left(34,68,300 \mathrm{e} 600 \mathrm{~g} \mathrm{ha}^{-1}\right) \mathrm{e}$ triclopyr (75, 150, 667 e $\left.1.334 \mathrm{~g} \mathrm{ha}^{-1}\right)$, além da testemunha sem aplicação. Foram coletados aquênios aos 15 dias após a aplicação, sendo estes submetidos ao teste de germinação, determinando-se a porcentagem e o indice de velocidade de germinação. Após 29 dias em germinação, verificou-se a viabilidade dos aquênios não germinados, através do teste de tetrazólio. A eficácia dos herbicidas foi avaliada por meio de notas visuais de controle aos 7 , 14, 21 e 28 DAA. Conclui-se que para o controle total de S. grisebachii, em estádio reprodutivo, é necessária a aplicação de $1.334 \mathrm{~g} \mathrm{ha}^{-1}$ de triclopyr. Nesse estádio, a planta apresentou grande tolerância ao glyphosate e também ao paraquat. Quanto às características germinativas da progênie, o herbicida triclopyr nas doses de 150 e $667 \mathrm{~g} \mathrm{ha}^{-1}$ promoveu redução na velocidade de germinação e na viabilidade, enquanto o glyphosate e paraquat não proporcionaram efeito.
\end{abstract}

Palavras-chave: Synedrellopsis grisebachii, controle químico, poder germinativo.

\begin{abstract}
Synedrellopsis grisebachii is a weed of great importance for pastures in Brazil, presenting outstanding aggressiveness, with its control being thus desirable for successful forage production. The aim of this work was to evaluate the chemical control of S. grisebachii at their reproductive phase and their effects on the germination characteristics of the weed's achenes. The treatments consisted of applying the herbicides glyphosate $\left(100,200,900\right.$, and $\left.1.800 \mathrm{~g} \mathrm{ha}^{-1}\right)$, paraquat $\left(34,68,300\right.$, and $\left.600 \mathrm{~g} \mathrm{ha}^{-1}\right)$ and triclopyr $\left(75,150,667\right.$, and $\left.1.334 \mathrm{~g} \mathrm{ha}^{-1}\right)$ and the control without application. Achenes were collected at 15 days after application and were submitted to germination tests to determine germination percentage and speed. After 29 days of germination, the viability of non-germinated achenes was verified by the tetrazolium test. The effectiveness of the herbicides was evaluated by visual scores of the control at 7, 14, 21, and 28 DAA. It was concluded that the control of $\mathbf{S}$. grisebachii at the reproductive stage requires application of $1.334 \mathrm{~g}$ triclopyr ha-1. At this stage, the plant was highly tolerant to glyphosate and to paraquat, as well. For the germination characteristics of the progeny, triclopyr at doses of 150 and $667 \mathrm{~g} \mathrm{ha}^{-1}$ promoted a reduction in the germination rate and viability, while glyphosate and paraquat had no effect.
\end{abstract}

Keywords: Synedrellopsis grisebachii, chemical control, germination power.

1 Recebido para publicação em 1.6.2011 e aprovado em 4.4.2012.

2 Engo-Agrōe, Dep. de Biologia Aplicada a Agropecuária, Faculdade de Ciências Agrárias e Veterinárias, Universidade Estadual Paulista "Júlio de Mesquita Filho" - FCAV/UNESP, Campus Jaboticabal. Jaboticabal-SP, Brasil, <paulogiancotti@gmail.com>; ${ }^{3}$ Professor, Dr., Dep. de Biologia Aplicada a Agropecuária, FCAV/UNESP, Via de acesso Prof. Dr. Paulo D. Castellane, s/n, Zona Rural, 14884-900 Jaboticabal-SP, Brasil, <plalves@fcav.unesp.br>; ${ }^{4}$ Mestre em Produção Vegetal, Dep. de Biologia Aplicada a Agropecuária, FCAV/UNESP, <micheliyamauti@yahoo.com.br>; ${ }^{5}$ Engo-Agro ${ }^{\circ}$, Dep. de Produção Vegetal. Escola Superior de Agricultura Luís de Queiroz, Universidade de São Paulo-ESALQ/USP, Piracicaba-SP, Brasil, <arthuragro07@hotmail.com>.

Planta Daninha, Viçosa-MG, v. 30, n. 2, p. 335-340, 2012 


\section{INTRODUÇÃO}

O agriãozinho (Synedrellopsis grisebachiiAsteraceae) é uma das plantas daninhas mais frequentes em pastagens das regiões CentroSul e Centro-Oeste do Brasil e sua presença vem aumentando também em lavouras perenes. Apresenta considerável desenvolvimento vegetativo e, apesar do hábito prostrado, consegue dominar facilmente gramineas forrageiras, principalmente se superpastoreadas (Yamauti, 2006). Considerando sua grande ocorrência e agressividade, justifica-se plenamente a preocupação em conhecer sua biologia e controlá-lo.

Dos métodos de controle das plantas daninhas, o químico é o mais difundido, desempenhando muito bem o seu papel, se utilizado de forma correta (Lorenzi, 2006). Além de proporcionar o controle, os herbicidas podem também interferir na biologia da planta daninha, prejudicando a reprodução (Neves et al., 1998), reduzindo a produção de sementes na planta-mãe ou, ainda, alterando a viabilidade destas (Azlin \& McWhorter, 1981; Andres \& Fleck, 1994). Esse fato torna-se importante, visto que as plantas daninhas que escapam aos métodos iniciais de controle ou que emergem tardiamente podem produzir quantidades de sementes que asseguram infestações nos anos subsequentes (Neves et al., 1998).

Os herbicidas podem apresentar diferentes mecanismos de ação na planta, ou seja, promovem diferentes reações, desde o contato do produto com a planta até a sua morte. Esses produtos podem ser classificados pela sua mobilidade nas plantas como herbicidas de ação sistêmica, como o glyphosate (sal de isopropilamina de $\mathrm{N}$-(fosfonometil)-glicina) e o triclopyr (éster butoxietílico do ácido 3,5,6tricloro-2- piridiloxiacético), ou imóveis, como o paraquat (1,1'-dimetil-4,4'-dicloreto de piridilio, ín) (Rodrigues \& Almeida, 2005).

O glyphosate, quando aplicado em pósemergência da cultura de soja convencional, cerca de três semanas antes da colheita, proporcionou efeito negativo no poder germinativo das suas sementes (Azlin \& Mcwhorter, 1981; Jeffery et al., 1981; Cerkauskas et al., 1982). Após a aplicação, o glyphosate parece ser translocado para os meristemas das sementes em desenvolvimento, mas não para aquelas já desenvolvidas anteriormente (Whigham \& Stoller, 1979). Efeitos prejudiciais sobre a progênie também foram observados com subdoses do mimetizador de auxina 2,4-D em trigo (Muzik, 1970). Por outro lado, Durigan \& Carvalho (1980) encontraram germinação e vigor de sementes sempre maiores na soja tratada com paraquat, ainda que as diferenças não tenham sido significativas em relação às sementes de plantas que não receberam o herbicida. Contudo, os resultados do efeito de herbicidas sobre o poder germinativo de sementes de plantas cultivadas são controversos, como os relatados por Bovey et al. (1975), com sorgo, e Ratnayake \& Shaw (1992), Neves et al. (1998) e Inoue et al. (2003), com soja. Não foram encontrados relatos de efeitos de herbicidas sobre aquênios de Asteraceae.

O objetivo deste trabalho foi avaliar o controle químico de Synedrellopsis grisebachii na fase reprodutiva e as suas consequências sobre as características germinativas dos aquênios da planta daninha.

\section{MATERIAL E MÉTODOS}

Aquênios de agriãozinho (Synedrellopsis grisebachii) coletados pela Faculdade de Ciências Agrárias e Veterinárias, campus de Jaboticabal, SP, foram postos para germinar em vasos de $5 \mathrm{~L}$, contendo três partes de solo (LV distrófico) para uma parte de adubo orgânico (esterco bovino curtido), em casa de vegetação. Dez dias após a emergência, as plântulas foram desbastadas, deixando-se uma planta por vaso. Os vasos foram acondicionados sobre pratos plásticos de maior diâmetro, para facilitar a coleta dos aquênios maduros que eventualmente se desprendiam das plantas.

Quando as plantas se apresentavam em plena frutificação, aos 150 dias após a semeadura, foi realizada a aplicação dos tratamentos, que constaram de quatro doses dos herbicidas glyphosate (Roundup ${ }^{\circledR}$ Original a 100, 200, 900 e $1.800 \mathrm{~g} \mathrm{ha}^{-1}$ e.a.), paraquat (Gramoxone ${ }^{\circledR} 200$ a 34, 68, 300 e 600 g ha $^{-1}$ i.a.) e triclopyr (Garlon $480 \mathrm{BR}^{\circledR}$ a 75, 150, 667 e $1.334 \mathrm{~g} \mathrm{ha}^{-1}$ i.a.), com uma testemunha sem aplicação, todos com quatro repetições. $\mathrm{Na}$ aplicação, utilizou-se pulverizador costal pressurizado com $\mathrm{CO}_{2}$, com quatro pontas de pulverização do tipo XR 110 02, regulado 
para aplicar volume de calda de $150 \mathrm{~L} \mathrm{ha}^{-1}$. O delineamento experimental foi em blocos casualizados.

O controle proporcionado pelos tratamentos foi avaliado visualmente aos 7, 14, 21 e 28 dias após a aplicação (DAA), usando escala de controle de 0 a 100 proposta pela ALAM. No período de sete a quinze dias após a aplicação, foram coletados os aquênios presentes em cada prato plástico, que se desprenderam naturalmente da planta-mãe, para serem submetidos ao teste de germinação. Após esse período não foi mais possivel a coleta, dada a injúria das plantas-mãe, proporcionada por alguns dos tratamentos.

O agriãozinho apresenta três tipos de aquênios, sendo escolhidos para o teste somente aqueles originados de flósculos hermafroditos, que possuem as faces levemente convexas e a ala membranácea lacinada (Kissmann \& Groth, 1992). Em laboratório, 15 aquênios por parcela (prato plástico) previamente selecionados foram postos para germinar em caixas tipo gerbox, contendo papel-filtro autoclavado, umedecido com $7 \mathrm{~mL}$ de água, e acondicionadas em câmara de germinação (CDG) com $14 \mathrm{~h}$ luz e $10 \mathrm{~h}$ escuro, com temperatura alternada de $30 / 15^{\circ} \mathrm{C}-$ condições ideais para a germinação de S. grisebachii, segundo Yamauti (2006). Os aquênios permaneceram 30 dias na CDG, sendo umedecidos diariamente com solução de nistatina a $0,2 \%(\mathrm{v} / \mathrm{v})$, quando também foi realizada a contagem dos aquênios germinados. A avaliação da germinação foi realizada diariamente, sempre no mesmo horário, efetuando-se a contagem e retirada de sementes germinadas durante 30 dias; foram determinados a germinação acumulada, a germinação final (\%) e o índice de velocidade de germinação (IVG) (Maguire, 1962):

$$
I V G=\frac{G 1}{N 1}+\frac{G 2}{N 2}+\ldots+\frac{G n}{N n}
$$

Os aquênios não germinados foram seccionados longitudinal-diagonalmente, evitando-se atingir o eixo embrionário. Em seguida, eles foram submetidos ao teste de tetrazólio a $0,2 \%(\mathrm{v} / \mathrm{v})$, sendo imersos totalmente na solução, em placas de Petri envolvidas em papel-alumínio e mantidas a $30{ }^{\circ} \mathrm{C}$ no escuro e em CDG por 18 horas (Brasil, 2009). As sementes que apresentaram coloração púrpura na região embrionária, somadas às germinadas, foram utilizadas na determinação do percentual de viabilidade.

$A$ análise de variância pelo teste $\mathrm{F}$ foi utilizada para avaliar o efeito dos tratamentos sobre as variáveis analisadas; posteriormente, para comparação das médias dos tratamentos, utilizou-se o teste de Tukey a $5 \%$ de probabilidade.

\section{RESULTADOS E DISCUSSÃO}

O paraquat proporcionou maior controle dos 7 aos 14 dias após a aplicação (DAA), quando comparado aos dois outros herbicidas; a sua maior dose (600 $\left.\mathrm{g} \mathrm{ha}^{-1}\right)$ manteve um excelente controle até os 14 DAA, após o qual decresceu, não superando os 60\% aos 28 DAA (Figura 1). A redução com o decorrer do tempo pode ser explicada pelo rápido e vigoroso rebrote apresentado pela planta daninha após a perda de área foliar.

O controle proporcionado pelo triclopyr foi crescente com o decorrer das avaliações, e suas duas maiores doses superaram as de paraquat aos 28 DAA. Nessa ocasião, a dose de $1.334 \mathrm{~g} \mathrm{ha}^{-1}$ de triclopyr proporcionou excelente controle da planta daninha (95\%), com controle total (100\%) obtido em 28 DAA - momento em que a dose de $667 \mathrm{~g}^{-1} \mathrm{a}^{-1}$ também proporcionou excelente controle (93\%). O efeito deletério desse herbicida foi lento e gradual, quando comparado ao do paraquat.

O glyphosate proporcionou lento controle de S. grisebachii (Figura 1). Esse herbicida, no decorrer do período experimental, não proporcionou controle superior a $60 \%$, mesmo em sua maior dose, o que demonstra a elevada tolerância dessa planta daninha ao herbicida. Esse resultado corrobora pesquisa de Procópio et al. (2006), os quais afirmam que $S$. grisebachii tem alta tolerância ao glyphosate.

Os aquênios coletados de plantas tratadas com glyphosate nas maiores doses apresentaram alta porcentagem de germinação (90\%), não diferindo da germinação obtida nas menores doses e na testemunha (Figura 2). Assim como o glyphosate, o triclopyr também 


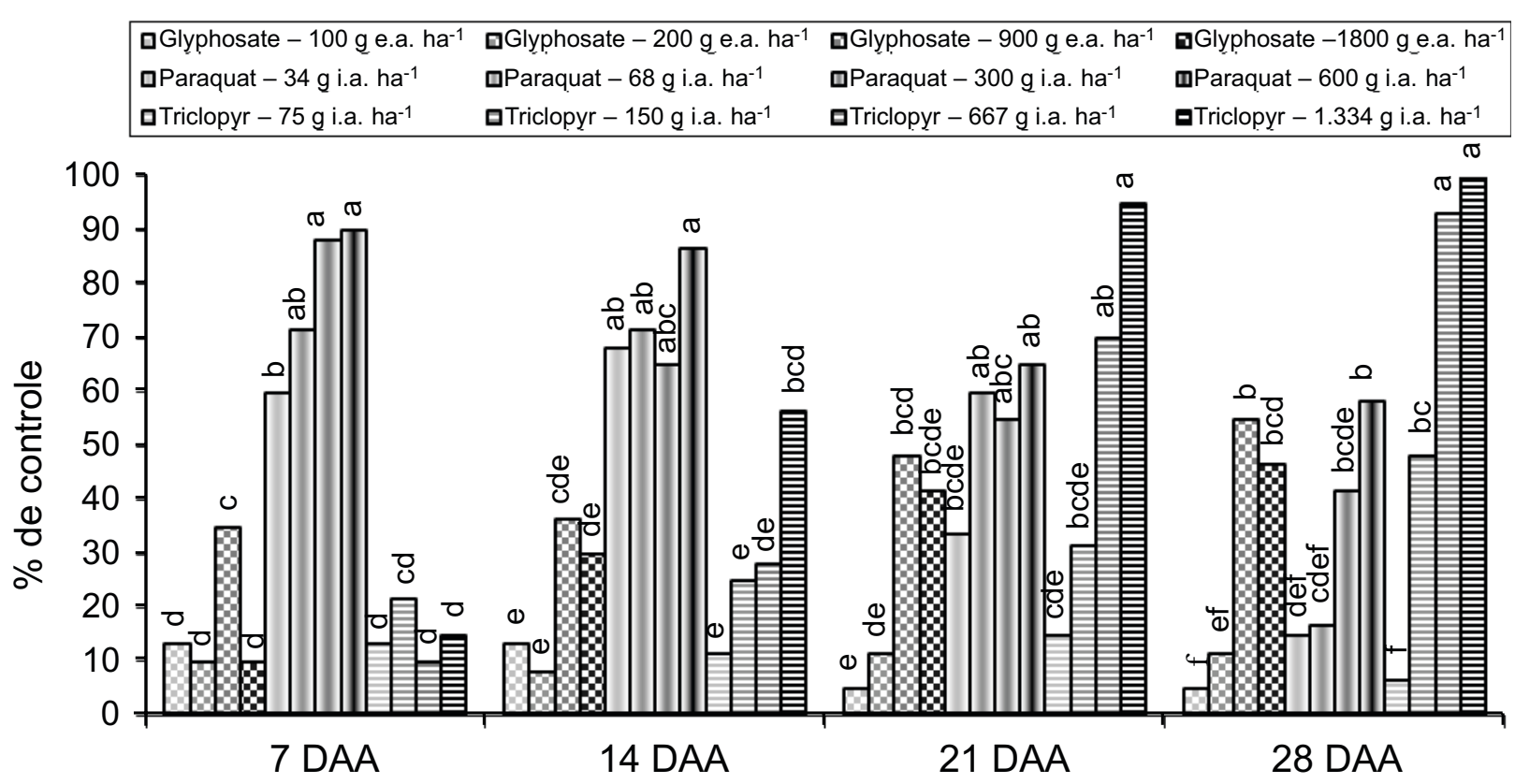

Figura 1 - Controle de S. grisebachii, avaliado em quatro períodos após a aplicação de doses crescentes de glyphosate, paraquat e triclopyr. Médias seguidas por mesma letra dentro de cada período não diferem entre si a 5\% pelo teste de Tukey.

proporcionou alta germinação à progênie quando em maior dose, porém as duas menores doses reduziram significativamente o poder germinativo.

Quanto menor a dosagem de paraquat, maior foi a germinação dos aquênios de agriãozinho - uma tendência contrária à apresentada pelos outros herbicidas estudados. Apesar disso, os tratamentos com o dessecante não diferiram estatisticamente da testemunha - o mesmo resultado foi encontrado por Inoue et al. (2003) ao aplicarem o paraquat na dose de 400 g i.a. ha ${ }^{-1}$ em plantas de soja. Durigan \& Carvalho (1980) e Ratnayake \& Shaw (1992) também não constataram efeito sobre a germinação com a aplicação do dessecante.

Os dados obtidos nesta pesquisa estão em acordo com os trabalhos realizados por Ratnayake \& Shaw (1992) e Bovey et al. (1975), nos quais não ocorreram efeitos negativos do herbicida glyphosate sobre a germinação de sementes de soja.

As duas menores doses de triclopyr foram as que proporcionaram maior redução na germinação dos aquênios, sendo inferior a $6 \%$ com a dose de $150 \mathrm{~g} \mathrm{ha}^{-1}$, diferindo estatisticamente da testemunha não tratada. Esse efeito de redução está de acordo com Muzik (1970), que encontrou efeito semelhante ao aplicar subdoses de 2,4-D em trigo. Segundo Tu et al. (2001), baixas concentrações de triclopyr podem estimular a sintese de RNA, DNA e

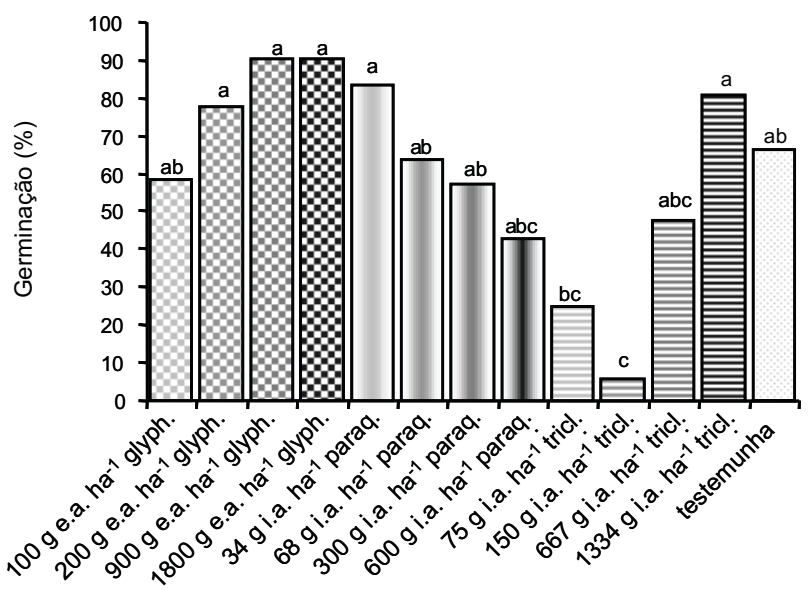

Figura 2 - Porcentagem de germinação dos aquênios de S. grisebachii após a aplicação de doses crescentes de glyphosate (glyph.), paraquat (paraq.) e triclopyr (tricl.) na planta-mãe. Colunas sob mesma letra minúscula representam médias que não diferem significativamente entre si a 5\% de probabilidade pelo teste de Tukey. 
proteínas; assim, o código genético poderia ser, de algum modo, transmitido para a progênie, levando ao crescimento descontrolado e destruição do tecido vascular. Em contrapartida, com as duas doses mais altas não houve grande diferença em relação à testemunha, o que pode ser devido a um impedimento na translocação do herbicida para o embrião ou órgãos de reserva das sementes.

A velocidade de germinação dos aquênios oriundos das plantas tratadas com paraquat chegou a atingir um indice de 6,3, enquanto os aquênios não tratados apresentaram valor de 2,2. Já o triclopyr diminui a velocidade de germinação quando em doses reduzidas, com as quais o índice foi de apenas 0,3 (Figura 3).

Com o aumento da dosagem de paraquat, a viabilidade foi reduzida a 57\%. A desfolha que o paraquat causou no agriãozinho pode ter impedido o transporte de fotoassimilados para os aquênios em formação e, por conseguinte, estes tiveram sua viabilidade comprometida (Figura 4).

A dose de $150 \mathrm{~g} \mathrm{ha}^{-1}$ de triclopyr foi o tratamento que mais reduziu a viabilidade dos aquênios (31\%). Com a aplicação de glyphosate, a viabilidade dos aquênios não sofreu alteração, permanecendo próxima a $90 \%$.

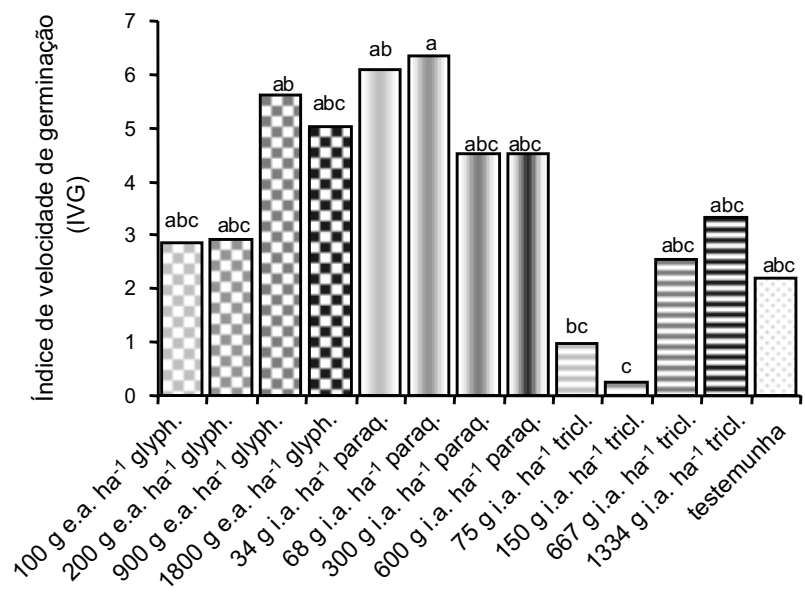

Figura 3 - Índice de velocidade de germinação (IVG) dos aquênios de $S$. grisebachii após a aplicação de doses crescentes de glyphosate (glyph.), paraquat (paraq.) e triclopyr (tricl.) na planta-mãe. Colunas sob mesma letra minúscula representam médias que não diferem significativamente entre si a $5 \%$ de probabilidade pelo teste de Tukey.

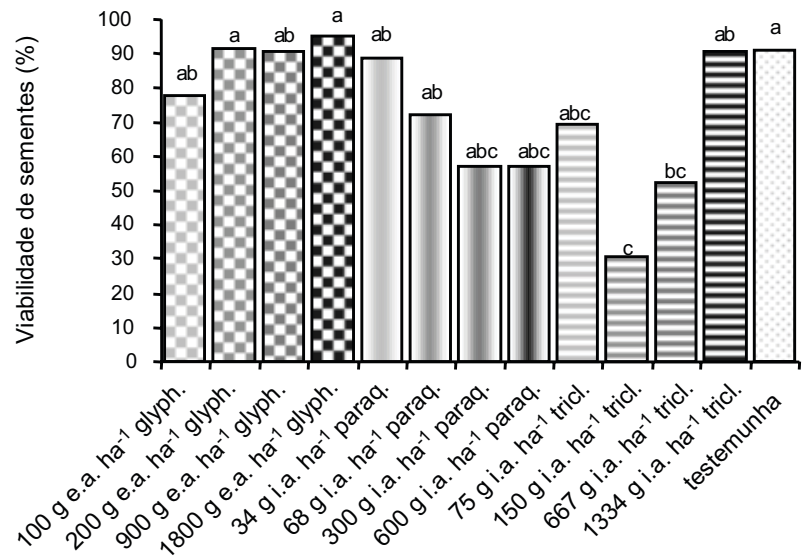

Figura 4 - Porcentagem de sementes viáveis dos aquênios de S. grisebachii após a aplicação de doses crescentes de glyphosate (glyph.), paraquat (paraq.) e triclopyr (tricl.) na planta-mãe. Colunas sob mesma letra minúscula representam médias que não diferem significativamente entre si a 5\% de probabilidade pelo teste de Tukey.

Para o controle total de S. grisebachii, em estádio reprodutivo, é necessária a aplicação de triclopyr na dose de 1.334 g i.a. ha ${ }^{-1}$. Nesse estádio, a planta foi muito tolerante ao glyphosate. Apresentou, também, tolerância ao paraquat, por se recuperar em um curto período de tempo. O herbicida triclopyr, nas doses de 150 e 667 g i.a. ha ${ }^{-1}$, reduziu a germinação e viabilidade dos aquênios de agriãozinho, enquanto glyphosate e paraquat não interferiram em suas características germinativas.

\section{LITERATURA CITADA}

ANDRES, A.; FLECK, N. G. Efeitos de imidazolinonas e sulfoniluréias sobre a produção de sementes e emergência de plântulas de quinquilho. Planta Daninha, v. 12, n. 2, p. $63-69,1994$.

AZLIN, W. R.; MCWHORTER, C. G. Preharvest effects of applying glyphosate to soybeans (Glycine max). Weed Sci., v. 29, n. 1, p. $123-127,1981$

BOVEY, R. W. et al. Preharvest desiccation of grain sorghum with glyphosate. Agron. J., v. 67, n. 5, p. 618-621, 1975.

BRASIL. Ministério da Agricultura. Pecuária e Abastecimento. Secretaria de Defesa Agropecuária. Regras para análise de sementes. Brasília: 2009. 399 p.

CERKAUSKAS, R. F. et al. Effect of three desiccant herbicides on soybean (Glycine max) seed quality. Weed Sci., v. 30, n. 5 , p. $484-490,1982$ 
DURIGAN, J. C.; CARVALHO, N. M. Aplicação, em précolheita, de dessecante em duas cultivares de soja (Glycine $\max$ L.) Merrill). I. Efeitos imediatos sobre a germinação e produção de sementes. Planta Daninha, v. 3, n. 1, p. 108-115, 1980.

INOUE, M. H. et al. Rendimento de grãos e qualidade de sementes de soja após a aplicação de herbicidas dessecantes. Ci. Rural, v. 33, n. 4, p. 769-770, 2003.

JEFFERY, L. S.; ENGLISH J. R.; CONNELL, J. The effects of fall application of glyphosate on corn (Zea mays), soybeans (Glycine max), and johnsongrass (Sorghum halepense). Weed Sci., v. 29, n. 2, p. 190-195, 1981.

KISSMANN, K. G.; GROTH, D. Plantas infestantes e nocivas. São Paulo: Basf Brasileira, 1992. 789 p.

LORENZI, H. Manual de identificação e controle de plantas daninhas: plantio direto e convencional. 6.ed. São Paulo: Instituto Plantarum, 2006. 339 p.

MAGUIRE, J. D. Speed of germination-aid in selection and evaluation for seedling emergence and vigor. Crop Sci., v. 2, n. 2, p. 176-177, 1962.

MUZIK, T. J. Weed biology and control. New York: McGraw-Hill Book, 1970. 273 p.
NEVES, R. et al. Ação de herbicidas sistêmicos não-seletivos sobre a progênie de soja quando aplicados durante a fase reprodutiva das plantas-mãe. Ci. Rural, v. 28, n. 3, p. $367-371,1998$.

PROCÓPIO, S. O. et al. Efeitos de dessecantes no controle de plantas daninhas na cultura da soja. Planta Daninha, v. 24, n. 1, p. 193-197, 2006.

RATNAYAKE, S.; SHAW, D. R. Effects of harvest-aid herbicides on sicklepod (Cassia obtusifolia) seed yield and quality. Weed Technol., v. 6, n. 4, p. 985-989, 1992.

RODRIGUES, B. N.; ALMEIDA, F. S. Guia de herbicidas. 5.ed. Londrina: Edição dos Autores, 2005. 592 p.

TU, M. et al. Weed control methods handbook: the nature conservancy. Abril de 2001. Disponível em: <http:// www.invasive.org/gist/products/handbook/20. Triclopyr.pdf $>$. Acesso em: 1ํago. 2010.

WHIGHAM, D. K.; STOLLER, E. W. Soybean desiccation by paraquat, glyfosate and ametryn to accelerate harvest.

Agron. J., v. 71, n. 4, p. 630-633, 1979.

YAMAUTI, M. S. Morfologia e germinação de Synedrellopsis grisebachii Hieron \& Kuntze (agriãozinho). B. Inf. SBCPD, v. 12, n. 4 , p. $7-8,2006$ 